\title{
Overview of the yeast genome
}

H. W. Mewes, K. Albermann, M. Bähr, D. Frishman,

A. Gleissner, J. Hani, K. Heumann, K. Kleine, A. Maierl, S. G. Oliver, F. Pfeiffer \& A. Zollner

Nature 387 (Suppl.) 9 (1997)

The display for chromosome 1 was incorrect as published owing to an error in the production process. The correct figure is shown here.
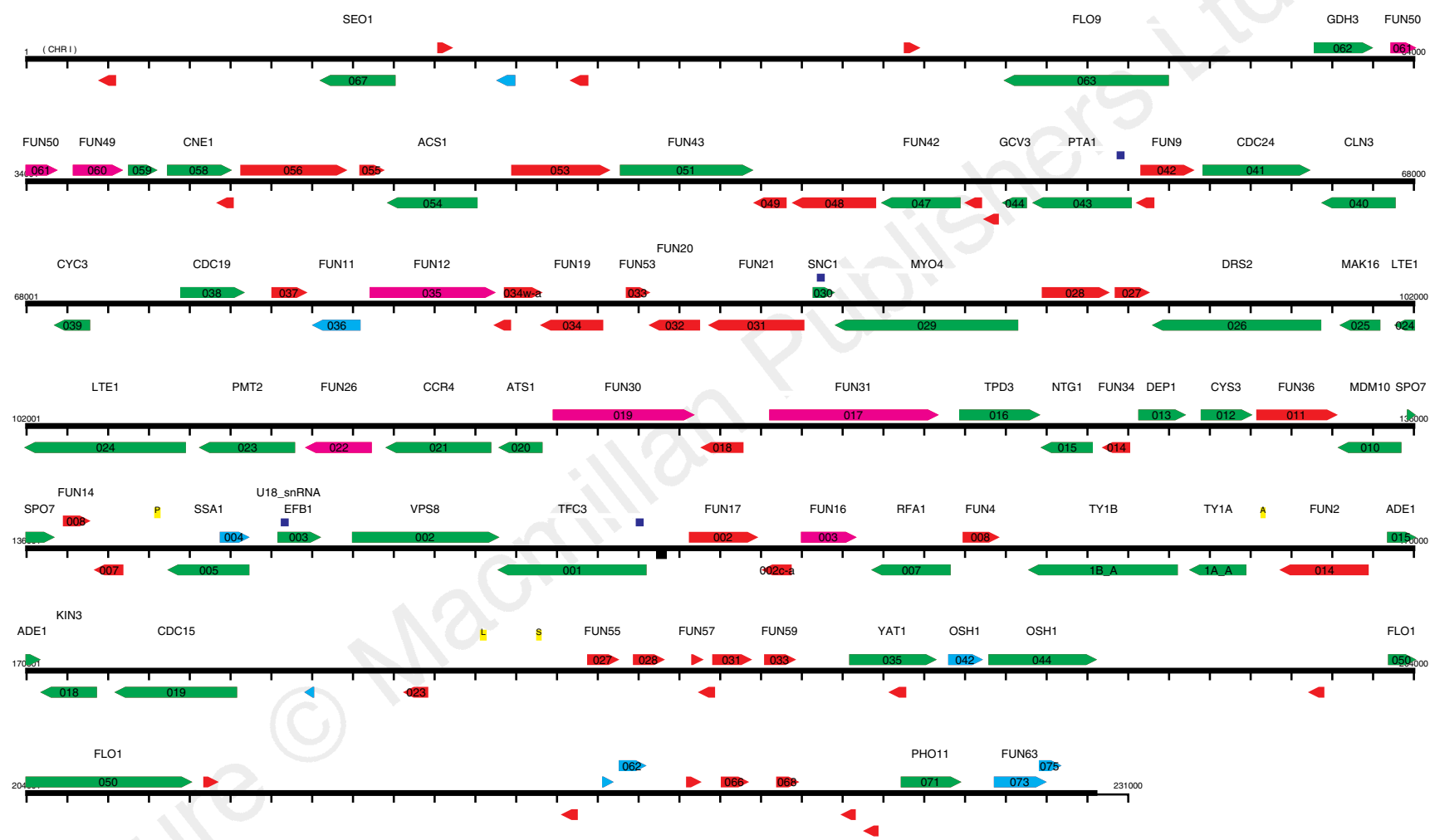